\title{
Dry Sliding Wear Response of a Modified Zinc-Based Alloy
}

\author{
B. K. Prasad*, A. K. Patwardhan** and A. H. Yegneswaran* \\ *Regional Research Laboratory (CSIR), Habibganj Naka, Bhopal-462026, India \\ ${ }^{* *}$ Metallurgical Engineering Department, University of Roorkee, Roorkee-247667, India
}

\begin{abstract}
An attempt has been made in this investigation to characterize the sliding wear response of a modified zinc-based alloy at the sliding speed of $2.68 \mathrm{~m} / \mathrm{s}$ over a range of applied pressures. A conventional zinc-based alloy (conforming to ZA 27) and a leaded-tin bronze (conforming to SAE 660) were also subjected to identical test conditions in order to assess the (wear) performance of the modified (zinc-based) alloy. A correlation has been established between the nature of the various microconstituents and the wear response of the alloys. Wear mechanisms have also been studied through the examination of wear surfaces, subsurfaces and debris.

The study clearly indicates that the presence of nickel and silicon comprising microconstituents led to a considerably increased wear and seizure resistance of the modified zinc-based alloy over its conventional counterpart. Further, zincbased alloys attained better wear resistance (prior to seizure) but inferior seizure pressure when compared with those of the bronze. As far as the extent of frictional heating is concerned, the conventional zinc-based alloy suffered from a maximum extent of heating while the bronze experienced the minimum. The response of the modified zinc-based alloy was intermediate between the two in this context. The modified alloy also attained improved thermal stability than the conventional (zinc-based) alloy.

In general, (microcracking assisted) adhesion was the predominant mechanism of material removal. However, abrasion was also observed to contribute to material loss. The zinc-based alloys experienced considerable wear induced subsurface deformation and formation of a stable transfer layer while such observations were weakly made in the case of the bronze due to the cracking tendency of the latter.
\end{abstract}

(Received February 29, 1996)

Keywords: sliding wear, zinc-based alloys, leaded-tin bronze, wear mechanisms, microstructure-wear property correlation

\section{Introduction}

Zinc-based alloys containing $8-27 \%$ aluminium, 1-3\% copper and a marginal quantity of magnesium have been observed to be potential materials which could be effectively substituted in place of bronzes, aluminium alloys, cast irons and steels for a variety of engineering applications ${ }^{(1)-(4)}$. It has been reported that inspite of a number of plus points, the (zinc-based) alloys suffer from property deterioration at temperatures above $\sim 100^{\circ} \mathrm{C}^{(1)(5)}$. Further, presence of the mentioned quantity of copper causes dimensional instability in the alloys ${ }^{(5)-(7)}$. The problem of dimensional instability is encountered in practice over a short span of time at high operating temperatures and becomes of great concern in applications needing close dimensional tolerances and involving the generation of high temperatures. As a result, the zinc-based alloys are prescribed for use at low speeds of rotation ${ }^{(1)-(3)}$.

It has been reported that dimensional changes taking place in the mentioned variety of the zinc-based alloys can be rectified through subjecting them to specified heat treating procedures ${ }^{(5)(8)}$. However, the alloys lose strength and hardness during the heat treatment ${ }^{(5)(8)(9)}$. One of the remedial measures to take care of the problem has been to reduce the quantity of copper in the alloys and compensate for the deterioration in the properties through the addition of other alloying elements ${ }^{(9)}$. Further, genera- tion of thermally stable phases in the alloys has been suggested to improve their elevated temperature properties $^{(10)-(12)}$.

Available information indicates that very limited efforts have been made towards understanding the effects of partial substitution of copper through high melting elements like silicon and manganese on the tribological properties of the zinc-based alloys ${ }^{(9)(10)(13)(14)}$. In view of the above, attempts have been made in this investigation to understand the wear response of a zinc-based alloy by partially replacing copper jointly by nickel and silicon. The wear tests have been conducted at a sliding speed (much) higher than normally prescribed for the zincbased alloys ${ }^{(1)-(3)}$. Wear mechanisms contributing to material loss have also been studied through the SEM examination of wear surfaces, subsurfaces and debris.

\section{Experimental}

\section{Alloy preparation}

Alloys (Table 1) were prepared by a liquid metallurgy route in the form of $20 \mathrm{~mm}$ diameter, $150 \mathrm{~mm}$ long cylindrical castings by using cast iron moulds. Alloying elements like zinc, aluminium, copper, nickel, tin, lead and magnesium used for preparing the alloys had purity levels greater than $99.95 \%$. Silicon was added in the form of BS LM6 alloy. Care was taken to add the low melting ele- 
Table 1 Chemical composition of experimental alloys.

\begin{tabular}{|c|c|c|c|c|c|c|c|c|}
\hline \multirow{2}{*}{ Alloy designation } & \multicolumn{8}{|c|}{ Elements, mass $\%$} \\
\hline & $\mathrm{Zn}$ & $\mathrm{Cu}$ & $\mathrm{Al}$ & $\mathrm{Mg}$ & $\mathrm{Sn}$ & $\mathrm{Pb}$ & $\mathrm{Ni}$ & $\mathrm{Si}$ \\
\hline $\begin{array}{l}\text { 1. Leaded-tin } \\
\text { bronze } \\
\text { (SAE 660) }\end{array}$ & 2.9 & $*$ & - & - & 7.2 & 7.3 & - & - \\
\hline $\begin{array}{l}\text { 2. Standard } \\
\text { zinc-based } \\
\text { alloy (ZA 27) }\end{array}$ & $*$ & 2.5 & 27.5 & 0.03 & - & - & - & - \\
\hline $\begin{array}{l}\text { 3. Modified } \\
\text { zinc-based } \\
\text { alloy }\end{array}$ & * & 1.0 & 27.5 & 0.03 & - & - & 0.9 & 1.0 \\
\hline
\end{tabular}

$*$ Balance

ments towards the final stage of melting to reduce their loss through vaporization.

\section{Specimen preparation}

Specimens of the conventional and modified zincbased alloys and the leaded-tin bronze (hardness 130 and 140 and $76 \mathrm{HV}$ respectively) were cut from the as-cast rods for microstructural characterization and sliding wear studies. Microstructural investigations were carried on $20 \mathrm{~mm}$ diameter, $15 \mathrm{~mm}$ thick specimens while $8 \mathrm{~mm}$ diameter, $53 \mathrm{~mm}$ long cylindrical pins were used for carrying out sliding wear tests.

\section{Sliding wear tests}

Sliding wear tests were conducted on polished cylindrical pins at the speed of $2.68 \mathrm{~m} / \mathrm{s}$ against an EN25 steel (0.3\% C, $0.7 \% \mathrm{Cr}, 2.5 \mathrm{Ni}, 0.5 \% \mathrm{Mo}$ and remaining $\mathrm{Fe})$ counterface heat treated to a hardness level of HRc 32. The test apparatus used for the purpose was a CameronPlint (U.K.) make pin-on-disc machine (Fig. 1) having the facility to record the temperature rise near the specimen surface with test duration with the help of a chromel-alumel thermocouple. Pressure on the specimens was applied in steps with the help of a hydraulic mechanism. The sliding distance in each case was limited to $500 \mathrm{~m}$ or to the distance traversed prior to the onset of (specimen) seizure; the term 'seizure' here means the occurrence of a situation leading to the adherence of a large amount of the fused mass of the (pin) specimen on to the disc, a high rate of material loss and temperature increase (near the specimen surface) and the generation of abnormal noise in the pin-disc assembly. The specimens were thoroughly cleaned prior to and after subjecting them to wear tests. Wear rates were computed by weight loss technique. A Mettler microbalance was used for weighing the specimens. Temperature rise near the specimen surface during the tests was recorded by inserting the thermocouple into the hole made at a distance of $1.5 \mathrm{~mm}$ from the mating surface.

\section{Microscopy}

Microstructural studies were carried out on metallographically polished specimens. The specimens of the bronze and the zinc-based alloys were etched with potassi-

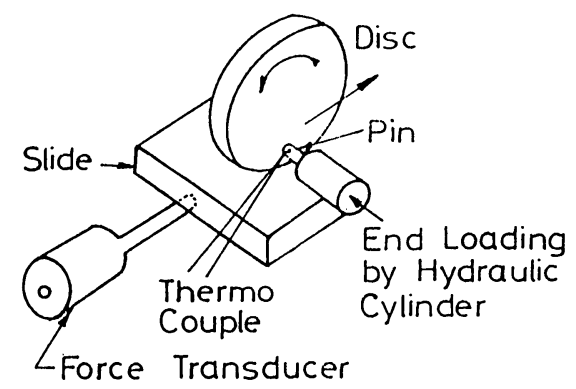

Fig. 1 A schematic representation of the pin-on-disc wear test configuration.

um dichromate and diluted aqua regia respectively prior to the microstructural examinations.

Wear surfaces, subsurface regions and debris of selected specimens were examined in the scanning electron microscope (SEM). Wear surfaces and debris particles were fixed on brass studs and sputtered with gold prior to their SEM examination. For characterizing the subsurface regions, the specimens were sectioned normal to the wear surface in the direction of sliding. This was followed by mounting the specimens in polyester resin, polishing them according to standard metallographic techniques and etching suitably. The samples were then fixed on brass studs and sputtered with gold prior to their SEM examination.

\section{Results}

\section{Microstructure}

Figure 2 reveals the microstructural characteristics of the alloys. The bronze showed primary $\alpha$ dendrites surrounded by the $\mathrm{Cu}-\mathrm{Sn}$ intermetallic compounds and particles of lead (Fig. 2(a), regions marked by A, B and C respectively). The conventional zinc-based alloy comprised primary $\alpha$ dendrites along with the eutectoid $\alpha+\eta$ and the metastable $\varepsilon$ phase in the interdendritic regions (Fig. 2(b), regions marked, by A, D and arrow respectively). On the contrary, the modified (zinc-based) alloy revealed nickel and silicon containing phases (Fig. 2(c), regions marked $E$ and $F$ respectively) along with the phases present in the conventional (zinc-based) alloy (Fig. 2(b)).

\section{Wear behaviour}

Wear rate of the alloys has been plotted as a function of applied pressure in Fig. 3. The wear rate was noted to increase with applied pressure. Moreover, two wear regimes were exhibited by the zinc-based alloys wherein the slope of the wear rate versus pressure curves was low in the beginning upto a specific pressure. Thereafter the slope of the curves became relatively higher. On the contrary, the bronze showed three different wear regimes (as indicated by three slopes in the wear rate versus pressure curves). In this case, the wear rate increased at a high rate initially followed by a reduction in the slope in the intermediate pressure range and finally an increased slope at still higher applied pressures until material seizure took 

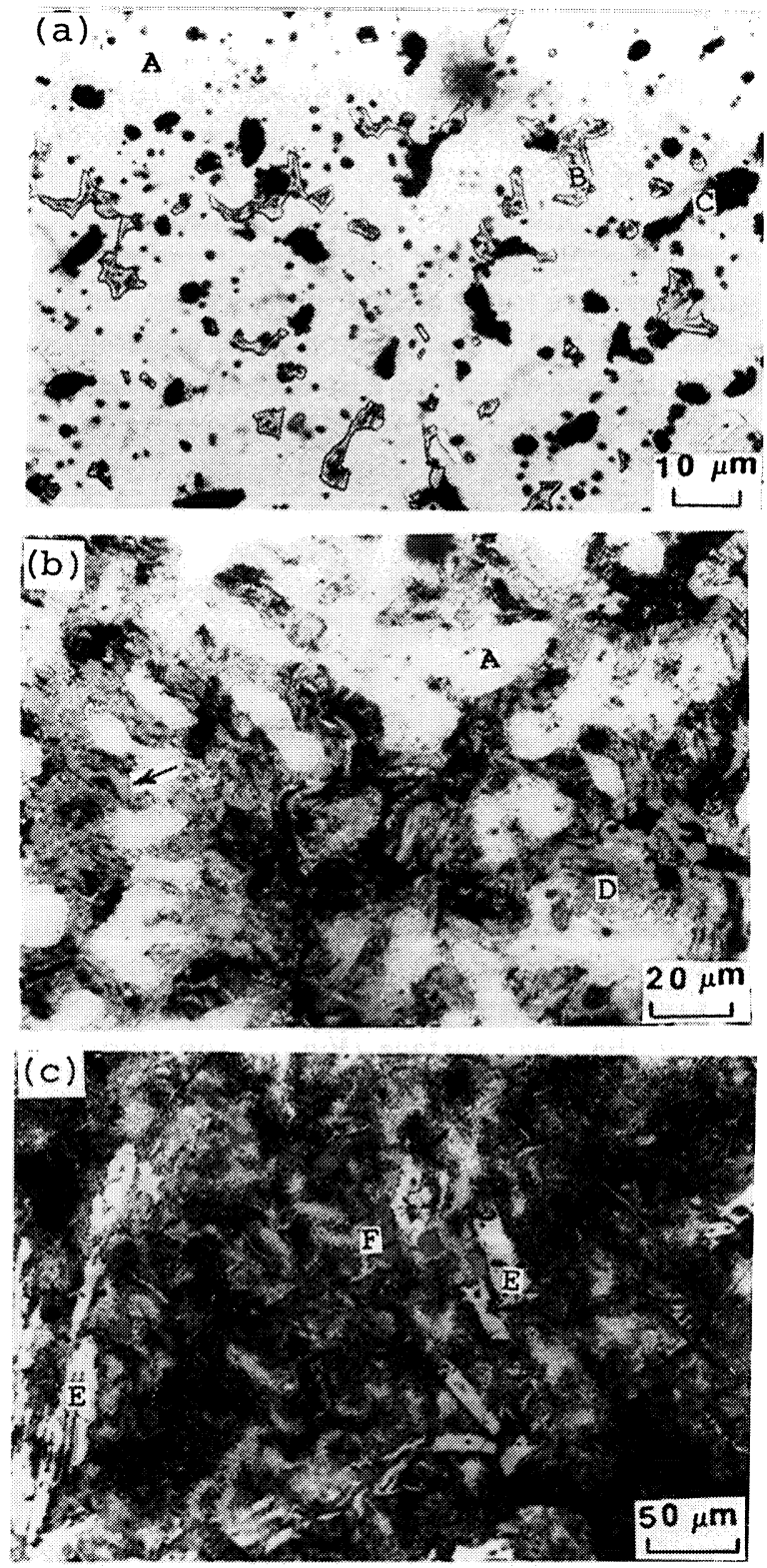

Fig. 2 Microstructure of (a) the bronze, (b) the conventional zincbased alloy and (c) the modified zinc-based alloy. [A: $\alpha, \mathrm{B}: \mathrm{Cu}-\mathrm{Sn}$ intermetallic compound, C: lead particles, D: eutectoid $\alpha+\eta$, Arrow: $\varepsilon, \mathrm{E}$ : nickel based compound and F: silicon].

place (Fig. 3). A comparison of the wear behaviour of the alloys shows significantly improved wear response (i.e. reduced wear rate and higher seizure pressure) of the modified zinc-based alloy over the conventional zincbased alloy while the bronze attained the best (wear) performance (Fig. 3).

Temperature rise (near the specimen surface) versus test duration plots are shown in Fig. 4. Initially a high rate of temperature rise was experienced by the specimens which was followed by a decrease in the rate of heating at longer test durations. Further at the minimum pressure, the modified zinc-based alloy displayed the minimum degree of (frictional) heating while that in the case of the conventional (zinc-based) alloy was the maximum, the bronze showing an intermediate behaviour (Fig. 4).

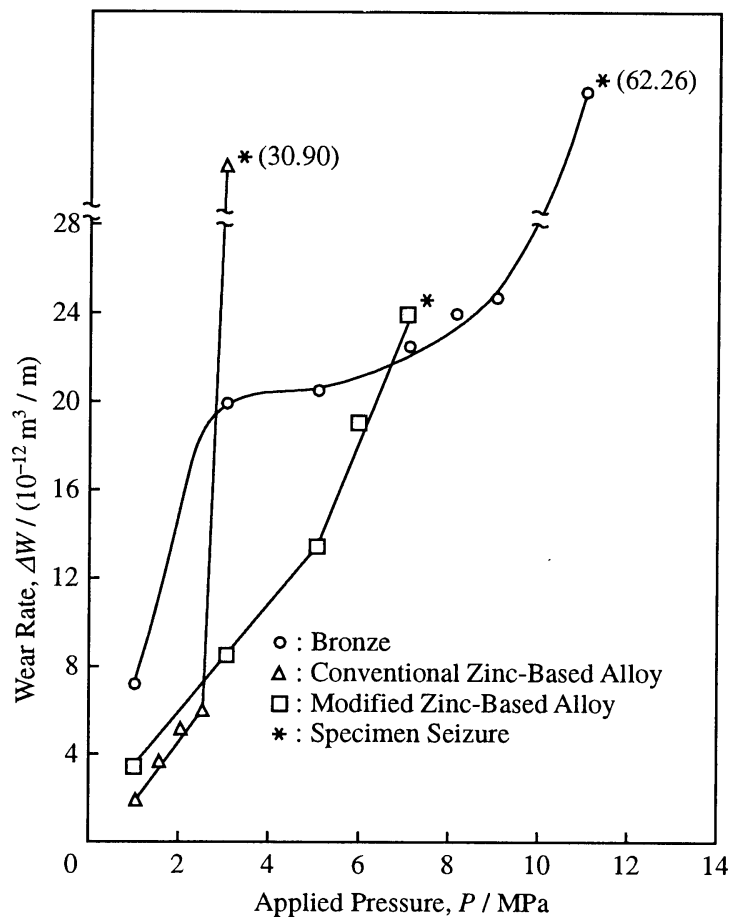

Fig. 3 Wear rate of the alloys plotted as a function of applied pressure.

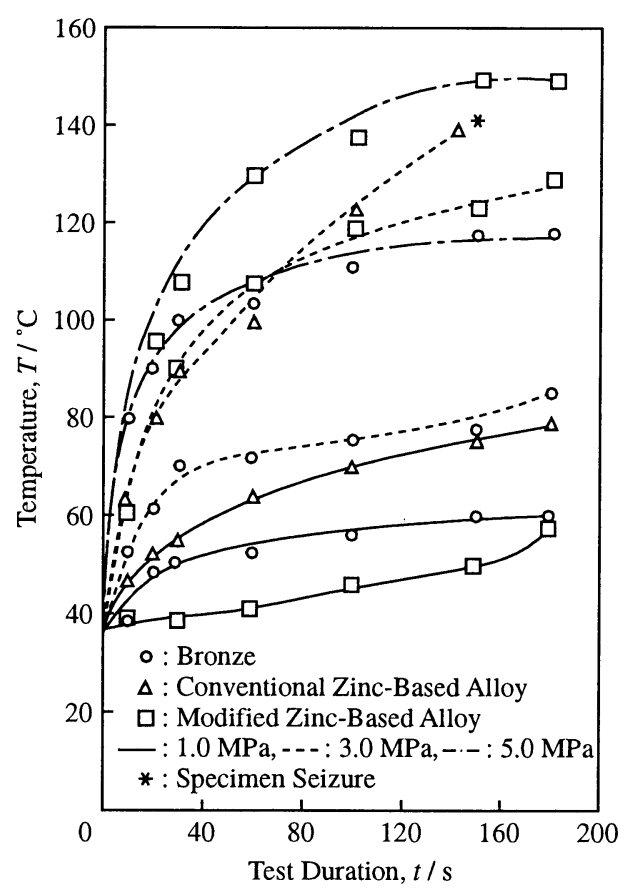

Fig. 4 Temperature rise versus test duration curves for the alloys.

However, the trend changed at higher applied pressures in the sense that the degree of frictional heating was the least for the bronze whereas it was more or less comparable for the zinc-based alloys (Fig. 4).

Maximum temperature rise near the specimen surface plotted as a function of applied pressure is shown in Fig. 5. In all the cases, the extent of maximum temperature rise increased with pressure. Moreover the conventional zinc-based alloy experienced the highest degree of heat- 


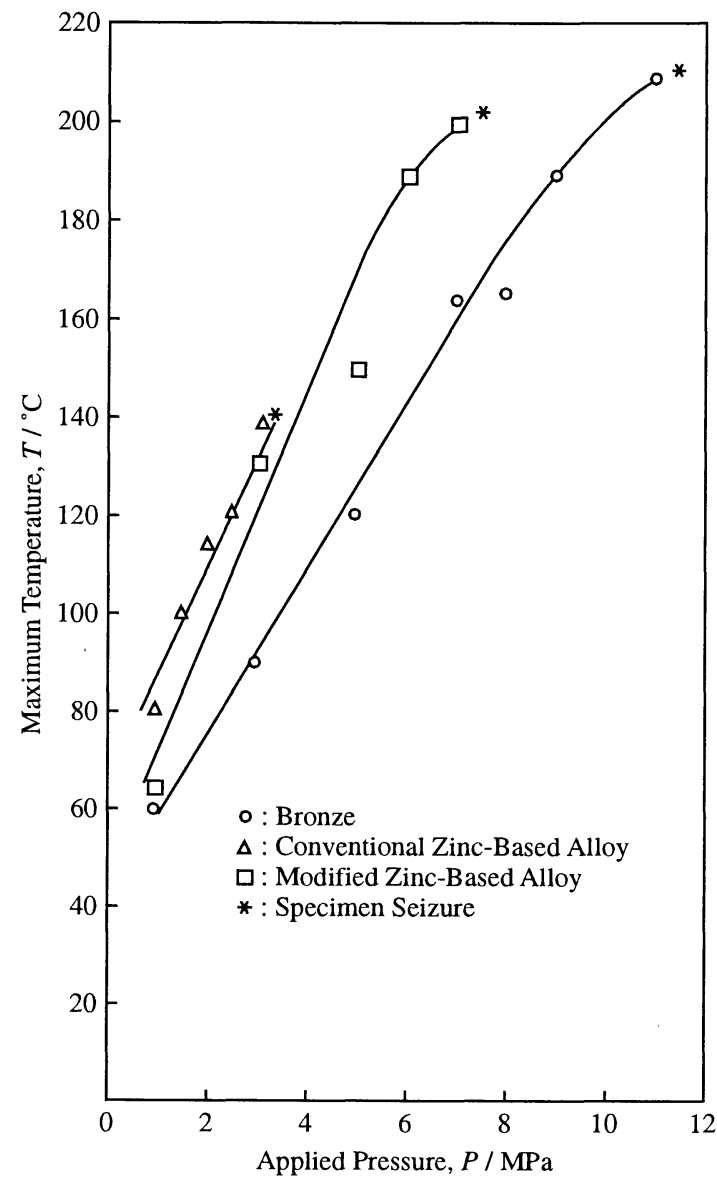

Fig. 5 Maximum temperature rise near the specimen surface plotted as a function of applied pressure.

ing while the bronze showed the minimum, the modified zinc-based alloy revealing an intermediate behaviour.

\section{Wear surface studies}

Figure 6 shows the wear surfaces of the alloys. The wear surfaces generated in the case of the bronze at low applied pressures were smooth except a few deeper (wear) grooves (Fig. 6(a), arrow-marked region). Similar were the observations made in the case of high applied pressures (Fig. 6(b)). However, the extent of surface damage increased in the latter case. Moreover, limited microcracking was also observed in general (Fig. 6(c)).

The conventional zinc-based alloy showed an increased extent of plastic deformation on its wear surface at low pressures (Fig. 6(d)) as compared to that of the bronze (Fig. 6(a)). Seizure of the former however led to considerably increased surface damage (Fig. 6(e)). A typical example of the entrapment of debris particles on the wear surface is shown in Fig. 6(f) (region marked by A). $\mathrm{X}$-ray dot mapping of iron and zinc (Fig. 6(g) and (h) respectively) corresponding to Fig. 6(f) confirmed the debris particle to be iron. A comparison of the wear surfaces of the conventional and modified zinc-based alloys showed relatively less damaged surfaces in the case of the modified alloy (Fig. 6(i)-(k)) over the latter (Fig. 6(d) and (e)). Further, sticking of fine as well as coarse debris was also observed in the former case (Fig. 6(i)-(k)).

\section{Subsurface characteristics}

Subsurface regions in general revealed plastically deformed areas close to the wear surface with/without microcracked regions attached to the bulk (Fig. 7). The subsurface regions of the bronze showed considerable microcracking along with limited wear induced plastic deformation close to the (wear) surface when the applied pressures were low (Fig. 7(a), top portion). Regions attached to the bulk which were in a process of being separated (to form wear debris) can also be noticed in Fig. 7(a) (region marked by A). Higher pressures led to an increased extent of plastic deformation while the degree of microcracking was less (Fig. 7(b)) over the ones at low pressures (Fig. 7(a)). Further, the thickness of the layer in a process of being detached from the bulk was also less in the latter case (Fig. 7(b), top portion). On the contrary, the conventional zinc-based alloy showed significant plastic deformation with practically no microcracking in the subsurface regions at low pressures (Fig. 7(c), top portion) while seizure led to limited microcracking (Fig. 7(d) and (e)). The modified zinc-based alloy also revealed significant plastic deformation along with fine regions attached to the bulk (Fig. 7(f), top portion). The degree of wear induced deformation was maximum in the near vicinity of the wear surface (Fig. 7, top portion) and reduced gradually, as evident from the decreasing extent of the fragmentation of the microconstituents, away from the wear surface. It may also be noted that a maximum of four distinct zones were observed namely a white structureless region, in the nearest vicinity of the wear surface, a heavily deformed region (indicated by very fine microconstituents) followed by the one showing the flow of the microconstituents in the direction of sliding and finally the bulk structure (Fig. 7(c), the regions marked by an arrow, B, C and D respectively).

\section{Wear debris analysis}

Wear debris of the bronze was observed to be coarser at low pressures (Fig. 8(a)) as compared to the one at higher applied pressures (Fig. 8(b) and (c)). Machining chips were also observed in the debris (Fig. 8(b), the region marked by A). A typical example of the presence of microcracks on the debris is shown in Fig. 8(c) (arrowmarked region). On the contrary, the debris size increased with pressure in the case of the conventional zinc-based alloy (Fig. 8(d) and (e). X-ray dot maps of iron and zinc (Fig. 8(f) and (g) respectively) corresponding to Fig. 8(e) also confirmed the presence of iron debris particles (region marked with B). The modified zinc-based alloy generated finer debris particles (Fig. 8(h)) than the conventional zinc-based alloy (Fig. 8(e)).

\section{Discussion}

Some of the wear characteristics of the specimens (Figs. 3-5) can be explained on the basis of their microstructural features (Fig. 2). It may be noted that $\alpha$ phase, i.e. a solid solution of tin in copper, (Fig. 2(a), the region 

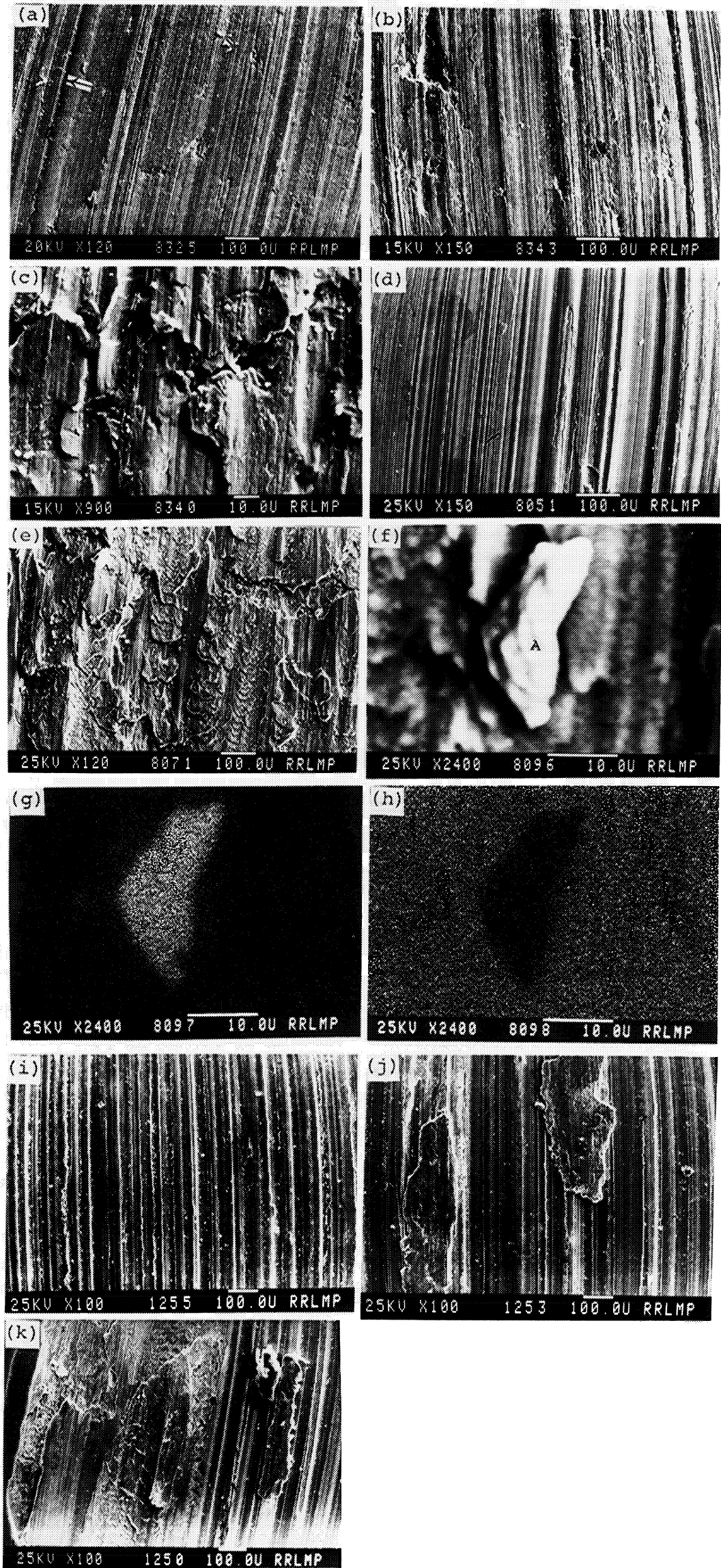

Fig. 6 Wear surface characteristics of ((a)-(c)) the bronze, ((d)-(h)) the conventional zinc-based alloy and ((i)-(k)) the modified zinc-based alloy: ((a), (d) and (i)) $1.0 \mathrm{MPa}$, ((b) and (c)) $11.0 \mathrm{MPa},((\mathrm{e})$ and (f)) $3.0 \mathrm{MPa},((\mathrm{g})$ and (h)) X-ray dot maps of iron and zinc respectively corresponding to $(\mathrm{f})$ and $((\mathrm{j})$ and $(\mathrm{k}))$ 7.0 $\mathrm{MPa}$. [Arrow: deeper wear groove, A: entrapped debris particle]. 


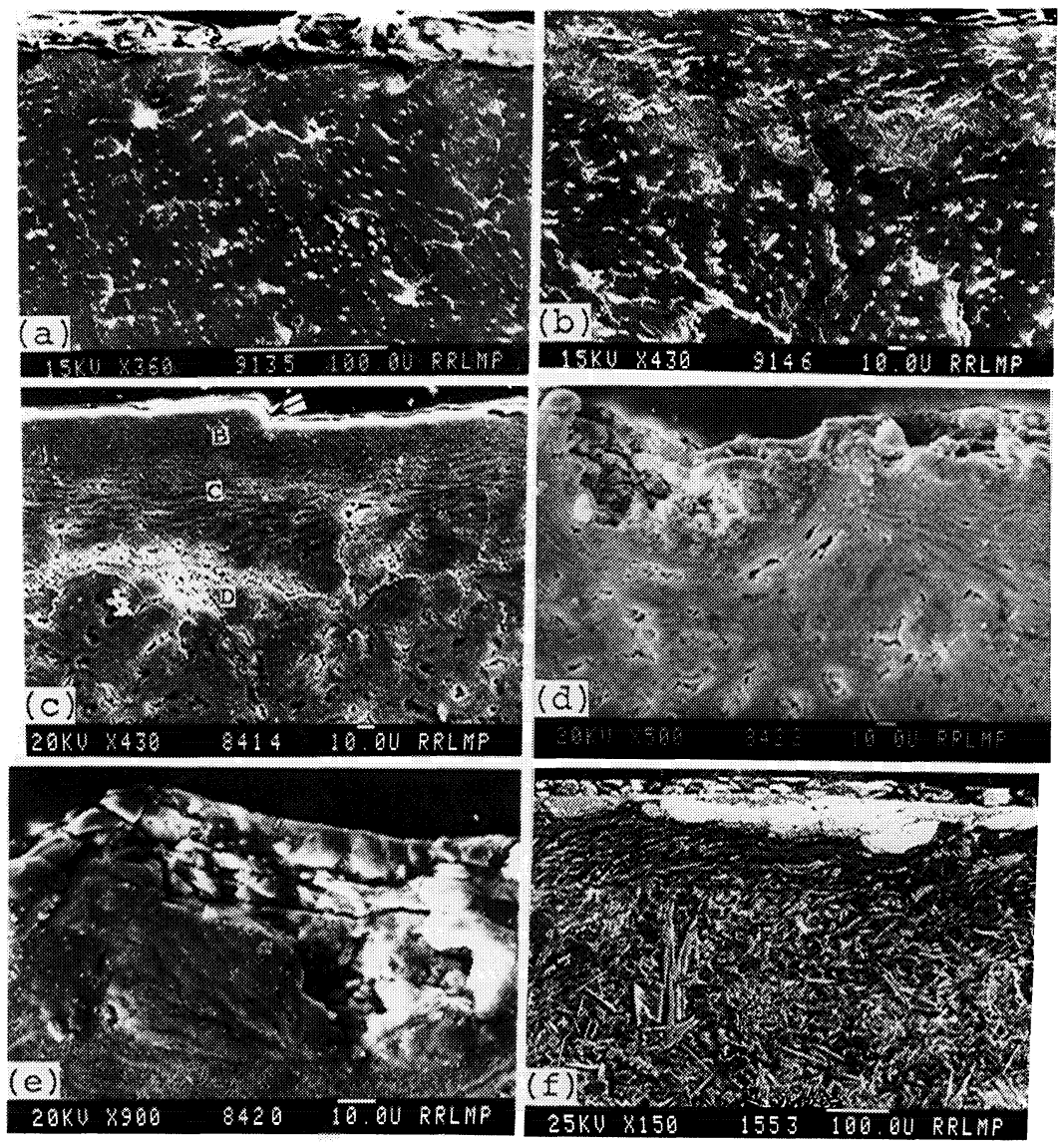

Fig. 7 Subsurface regions of ((a) and (b)) the bronze, ((c)-(e)) the conventional zinc-based alloy and (f) the modified zinc-based alloy: ((a) and (c)) 1.0 MPa, (b) 11.0 MPa, ((d) and (e)) 3.0 MPa and (f) 7.0 MPa. [A: region in a process of being separated from the wear surface, Arrow: white region, B: heavily deformed region: material flow in the sliding direction and D: unaffected bulk].

marked by A) in the bronze is a relatively softer and more ductile phase which provides support and compatibility to the hard and load bearing $\mathrm{Cu}-\mathrm{Sn}$ intermetallic compounds (Fig. 2(a), the region marked by B) and the lubricating lead particles (Fig. 2(a), the region marked by C). However, an optimum degree of heating is essential to be generated in order that the $(\alpha)$ phase performs in the desired manner and it allows the other microconstituents, such as the load bearing and the lubricating phases, to play their roles accordingly ${ }^{(15)(16)}$. In the event of the degree of (frictional) heating being less, cracking (preferably along the lead/matrix interfacial regions) takes place ${ }^{(10)(17)}$. Further, when the conditions are such that excessive heat is generated at the mating surfaces, the specimen tends to fuse with the counterface and seize ${ }^{(10)(17)(18)}$

In the low pressure regime, a higher slope in the wear rate versus applied pressure curves of the bronze (Fig. 3) could be attributed to the predominant microcracking tendency of the alloy (Figs. 6(c) and 7(a)) leading to the generation of coarse debris particles (Fig. 8(a)) under the conditions of less frictional heating (Figs. 4 and 5). Coarse debris particles have a tendency to engulf the lubricating lead particles. Under the circumstances, lead becomes unable to smear on the wear surface and fails to produce lubricating effect ${ }^{(15)(17)}$. On the contrary, higher applied pressures increased the extent of frictional heating (Figs. 4 and 5) reducing the microcracking tendency of the alloy (Fig. 7(b)). This made the conditions favourable for the (possible) formation of the lubricating film of lead ${ }^{(15)(17)}$ and reduce the slope of the wear rate curve (like in the intermediate pressure range) in Fig. 3. The generation of finer debris in this case (Fig. 8(b) and (c)) than at low pressures (Fig. 8(a)) further supports the increased probability of the formation of lead film on the wear surface ${ }^{(15)(17)}$. Increasing the pressure further caused the generation of more (frictional) heat (Figs. 4 and 5) leading to material seizure wherein the slope of the wear rate curve increased again (Fig. 3).

The nature of the microconstituents in the case of the (conventional as well as modified) zinc-based alloys was different than those of the bronze in the sense that the former comprised softer amd more ductile phases like $\alpha$ and $\eta$ (i.e. the solid solutions of zinc and aluminium in aluminium and zinc respectively) as shown in Fig. 2(b). Further, the major microconstituent i.e. $\eta$ in the zincbased alloys is lubricating in nature in view of its hexagonal structure having $c / a$ ratio larger than that of an ideal hexagonal close packed crystal ${ }^{(19)}$. The phase also effectively carries load because of its hexagonal structure $\mathrm{e}^{(20)}$. Thus, it is obvious that all the microconstituents in the conventional zinc-based alloy have low melting char- 



Fig. 8 Wear debris particles of ((a)-(c)) the bronze, ((d)-(g)) the conventional zinc-based alloy and (h) the modified zinc-based alloy: ((a) and (d)) 1.0 MPa, ((b) and (c)) $11.0 \mathrm{MPa}$, (e) 3.0 MPa, ((f) and (g)) X-ray dot maps of iron and zinc respectively corresponding to (e) and (h) 7.0 MPa. [A: machining chip, Arrow: microcrack and B: iron debris].

acteristics. As a result, the alloy showed lower wear rates at low pressures (prior to seizure) but reduced seizure resistance (Fig. 3). The presence of hard and thermally stable nickel and silicon comprising phases ${ }^{(10)}$ as shown in Fig. 2(c) (regions marked $\mathrm{E}$ and $\mathrm{F}$ respectively) improved the wear characteristics of the modified zinc-based alloy considerably (as evident from the reduced wear rates and increased seizure resistance) over the conventional zincbased alloy (Fig. 3).

Significantly higher rate of temperature rise near the specimen surface in the beginning of the tests (Fig. 4) could be attributed to the initial asperity-to-asperity mode of contact between the mating surfaces. These contacting asperities constitute only a minor fraction of the apparent area of contact. As a result, they are subjected to high stress conditions making them prone to yielding, oxidation and fragmentation ${ }^{(18)}$. The fragmented mass produces abrading action on the wear surface and increases the degree of heating (Fig. 4). However, as the asperities fragment, the real area of contact increases and the effective stress concentration reduces leading to the decrease in the rate of temperature rise (Fig. 4). The decrease in the rate of temperature rise could also be due to the attainment of the steady state heating.

Deeper wear grooves on the specimen surface (Fig. 6) could be due to the entrapment of iron debris derived from the disc surface and the fragmented hard microconstituents from the specimen surfaces ${ }^{(18)}$. The presence of the similar particles in the debris (Fig. 8(b) and (e)) substantiates the view further.

Different features of the (subsurface) regions below the wear surface (Fig. 7(c), regions marked by arrow, B, C and $D$ ) result from the varying degree of wear induced plastic deformation they undergo; the extent of deforma- 
tion decreases away from the wear surface and approaches zero in the region marked $\mathrm{D}$. The phenomenon has been discussed in detail elsewhere ${ }^{(21)-(24)}$.

A critical appraisal of the observations made in this investigation clearly indicates that there lies a wide scope to improve the wear response of zinc-based alloys through appropriate alloy design and development. The observation gains importance in view of the fact that it pertains to a higher speed of sliding than the ones normally prescribed for conventional zinc-based alloys ${ }^{(1)-(3)}$.

\section{Conclusions}

(1) Wear rate increased with pressure irrespective of the alloy composition. The conventional zinc-based alloy was most sensitive to pressure. The sensitivity of the modified zinc-based alloy reduced considerably over that of the conventional (zinc-based) alloy indicating better wear performance in the former case as a result of partially replacing copper with nickel and silicon. The bronze showed far better wear response than the zinc-based alloys.

(2) The zinc-based alloys showed mild wear up to a specified pressure as indicated by a lower slope of the wear rate versus pressure curves. The wear mode changed from the mild to severe one causing the slope of the wear rate curves to increase at higher pressures ultimately leading to material seizure. On the contrary, the bronze attained a higher rate of increase in the wear rate at low pressures due to the microcracking tendency of the alloy while the slope of the curve reduced (indicating mild wear) in the intermediate pressure range due to the suppressed cracking tendency of the alloy and increased possibility of the formation of lubricating (lead) film. At still higher applied pressures, material seizure occurred due to its fusion under the condition of excessive frictional heating leding to a further increase in the slope of the wear rate curve indicating the attainment of severe wear.

(3) Asperity-to-asperity contact in the beginning of the wear tests caused the load bearing asperities to fragment under high stress condition and cause abrasion on the surface. This led to initially higher rate of temperature rise with test duration. With the passage of time, a change in the mode of contact from asperity-to-asperity to area-to-area as well as the attainment of steady state heating decreased the rate of rise in temperature near the specimen surface.

(4) The wear response of the alloys could well be correlated with the characteristics of their wear surfaces, subsurface regions and debris particles wherein mild wear led to the generation of less damaged surface and subsurface regions and fine debris particles. On the contrary, severe wear formed more damaged/cracked subsurface regions and coarser debris, especially so in the case of the zinc-based alloys.

(5) Material removal in the bronze was dominated by the microcracking tendency of the material at low pressures whereas adhesive wear mainly became operative at higher pressures. On the other hand, the zinc-based alloys experienced adhesion over the entire range of applied pressures. At very high pressures, specimen seizure occurred by the adhesion of material on to the disc as a result of fusion.

(6) Abrasion was also observed to contribute considerably to material loss in addition to adhesion in all the cases. This was confirmed through the observation of deeper wear grooves and iron debris particles on the wear surface. The presence of iron mass in the debris particles further substantiated the view.

\section{REFERENCES}

(1) E. J. Kubel: Adv. Mater. Proc., 132 (1987), 51.

(2) K. J. Altorfer: Met. Prog., 34 (1982), 29.

(3) T. S. Calayag: Mining Eng., 35 (1983), 727.

(4) W. Mihaichuk: Proc. 12th Int. Die Cast. Cogr. Expo., Society of Die Casting Engineers (SDCE) Inc., USA, (1983), p. 1.

(5) E. Gervais, R. J. Barnhurst and C. A. Loong: J. Metals, 37 (1985), 43.

(6) K. Lohberg: Z. Metallkde., 74 (1983), 456.

(7) F. Klein: Proc. 13th Die Cast. Congr. Expo., Society of Die Casting Engineers (SDCE) Inc., USA, (1985), p. 1.

(8) E. Gervais, H. Levert and M. Bess: Trans. AFS, 68 (1980), 183.

(9) T. Savaskan apd S. Murphy: Wear, 116 (1987), 211.

(10) B. K. Prasad: Ph. D. Thesis, Met. Eng. Dept., University of Roorkee, Roorkee, India, (1994).

(11) H. X. Zhu and S. K. Liu: Composites, 24 (1993), 437.

(12) P. N. Dent and S. Murphy: Proc. Int. Sympo. Zinc-Aluminium (ZA) Cast Alloys, ed. by G. P. Lewis, R. J. Barnhurst and C. A. Loong, Canadian Institute of Metals (CIM), (1986), p. 127.

(13) P. P. Lee, T. Savaskan and E. Laufer: Wear, 117 (1987), 79.

(14) T. Ma, Q. D. Chen, S. C. Li and H. M. Wang: Proc. Int. Conf. Wear Mater., Vol. I, ed. by K. C. Ludema, American Society of Mechanical Engineers (ASME), (1989), p. 297.

(15) W. A. Glaeser: ibid., p. 255.

(16) Heat Treatment, Structure and Properties of Nonferrous Alloys, ed. by C. R. Brooks, ASM, Metals Park, Ohio, USA, (1982), p. 275.

(17) B. K. Prasad, A. K. Patwardhan and A. H. Yegneswaran: Mater. Sci. Technol., 12 (1996), 427.

(18) O. P. Modi, B. K. Prasad, A. H. Yegneswaran and M. L. Vaidya: Mater. Sci. Eng., 152A (1992), 235.

(19) Zinc and Its Alloys and Compounds, 1st edition, ed. by S. W. K. Morgan, Ellis Horwood Limited Publishers, Chicester, John Willey and Sons, (1985), p. 154.

(20) S. Murphy and T. Savaskan: Wear, 98 (1984), 151.

(21) D. A. Rigney and J. P. Hirth: Wear, 53 (1979), 345.

(22) S. L. Rice, H. Nowotny and S. F. Wayne: Wear, 74 (1981), 131.

(23) M. A. Moore and R. M. Douthwaite: Metall. Trans., 7A (1976), 1833.

(24) T. S. Eyre and A. Baxter: Tribology, Dec., (1972), 256. 